\title{
Left Atrial Isomerism in Afro-Caribbean Adolescents and Adults with no Intervention: Echocardiographic Findings
}

\author{
S Williams-Phillips, M Hoo Sang
}

\begin{abstract}
Left atrial isomerism (LAI) is a rare congenital anomaly usually associated with major or minor congenital cardiac lesions. Presentation beyond childhood is unusual as there is usually high morbidity of 63\% associated with the co-morbid major congenital cardiac lesions in the first year of life. The four index cases highlight the myriad cardiac lesions facilitating survival into adolescence and adulthood of this rare cardiac condition. Presented are markedly different echocardiographic findings of four cases of LAI in Afro-Caribbeans who had no intervention. Their diagnostic transthoracic echocardiographic findings are the focussed features of this article and the first documentation of isolated patent ductus arteriosus with LAI. Fascinating diagnostic chest X-ray findings of the LAI index cases are presented. They are the first cases of LAI documented in Afro-Caribbeans.
\end{abstract}

Keywords: Atrial isomerism, atrial septal defect, dextrocardia, patent ductus arteriosus, pulmonary stenosis

\section{Isomerismo Auricular Izquierdo en Adolescentes y Adultos Afrocaribeños Sin Intervención: Hallazgos Ecocardiográficos}

\author{
S Williams-Phillips, M Hoo Sang
}

\begin{abstract}
RESUMEN
El isomerismo auricular izquierdo (IAI) es una anomalía congénita rara, generalmente asociada con lesiones cardíacas congénitas mayores o menores. Es poco usual que se presente más allá de la infancia, debido a la alta morbilidad de $63 \%$ asociada con las principales lesiones cardíacas congénitas comórbidas en el primer año de vida. Los cuatro casos índices destacan la miríada de lesiones cardíacas que favorecen que la supervivencia alcance la adolescencia y la edad adulta en los casos de esta rara condición cardiaca. Se presentan hallazgos ecocardiográficos marcadamente diferentes de cuatro casos de IAI en afrocaribeños que no tenían ninguna intervención. Sus hallazgos ecocardiográficos transtorácicos diagnósticos son las características específicas en que se enfoca este artículo, y constituyen la primera documentación sobre el conducto arterioso persistente aislado, con IAI. Se presentan fascinantes hallazgos radiográficos torácicos diagnósticos de los casos índice de IAI. Se trata de la documentación de los primeros casos de IAI afrocaribeños.
\end{abstract}

Palabras claves: Isomerismo auricular, defecto septal auricular, dextrocardia, conducto arterioso persistente, estenosis pulmonar

West Indian Med J 2016; 65 (1): 204

\section{LEARNING OBJECTIVES}

Left atrial isomerism (LAI) is usually associated with severe non-cardiac and complex cardiac lesions. Survival is totally dependent on the co-morbid features and $61 \%$ usually die in in-

From: Andrews Memorial Hospital, TAI Wing, 27 Hope Road, Kingston 10, Jamaica, West Indies.

Correspondence: Dr S Williams-Phillips, Andrews Memorial Hospital, TAI Wing, 27 Hope Road, Kingston 10, Jamaica, West Indies. E-mail: sandrap@cwjamaica.com fancy. The four index cases highlight the myriad of cardiac lesions facilitating survival into adolescence and adulthood of this rare cardiac condition. This is the first documentation of isolated patent ductus arteriosus (PDA) with LAI. Diagnostic chest X-ray findings of the LAI index cases are presented as teaching tools.

\section{INTRODUCTION}

In LAI, also called polysplenia syndrome, situs ambiguus, heterotaxia, visceral heterotaxy, or bilateral left-sidedness, diag- 
nosis is made with a compilation of cardiac and non-cardiac abnormalities $(1,2)$. The diagnosis can be made radiographically by the presence of symmetrical, bilateral hyparterial bronchi on chest X-ray, morphologically at autopsy or on transoesophageal echocardiogram with bilateral morphological left atrial appendages with few pectinate muscles and a narrow hooked "snoopy's ears" appearance, bilateral bilobed lungs. Hupta (1982), ultrasonographically using transthoracic echocardiogram in subdiaphragmatic transverse view, confirmed the correlation between the anterior aorta and posterior hemiazygous vein being on the same side of the spine and interruption of the inferior vena cava with direct connection of the hepatic vein to the right atrium having a direct correlation with the diagnosis of LAI (1-4). Three of the four index cases had obvious hyparterial bronchi radiologically and scoliosis may have contributed to this radiological sign not being clearly evident in one case.

Cardiac defects occur in over 70\% and non-cardiac defects in $38 \%$ of patients. Cardiac defects occur at every level of the heart using sequential segmental analysis, starting with the cardiac position, and include dextrocardia $39 \%$, anomalous systemic and pulmonary veins $92 \%$, atrial septum with a myriad of interatrial defects from common atria $50 \%$, ostium primum, secundum atrial and coronary sinus defects. Cardiac defects at the atrioventricular level include atrio-ventricular septal defects $49 \%$, and ventricular septal defects which can be inlet, muscular or perimembranous. Cardiac defects at the ventricular level include "single ventricle", hypolastic ventricle $63 \%$, at the ventriculo-arterial level, transposition of the great vessels $16 \%$, pulmonary atresia or stenosis $27 \%$, aortic stenosis, both double-outlet right $32 \%$ and double-outlet left ventricles $5 \%$ and coarctation and hypolasia of the aorta. There are documented cases of "normal hearts" with LAI as high as $10 \%$ by Gilljam et al (4). Bilateral left-sidedness, with Dickenson et al (1979) confirming anomalous sinoatrial nodes and conducting system, have cardiac arrhythmias which have been noted to occur in over $30 \%$ of patients but as high as $71 \%$ by Eronen et al and some may rarely have congenital atrioventricular block (1-4). None of the four index cases had an arrhythmia which has helped with their overall longevity. Electrocardiogram (ECG) abnormalities noted for the four index cases were short P-R interval, superior P-axis, QRS right axis deviation and left axis deviation with a complete atrioventricular septal defect. There was biventricular hypertrophy with index cases 1 and 4, with "Swiss cheese" ventricular muscular septal defects and complete atrioventricular septal defect. In index case 2 with pulmonary hypertension, there was QRS right axis deviation, right atrial enlargement and right ventricular hypertrophy. The Table provides a summary of the ECG findings associated with each index case's structural anatomic findings.

Non-cardiac defects can affect every system in the body, in addition to polyspenia, abdominal and cardiac situs inversus and midline liver. Gastrointestinal anomalies include biliary atresia $11 \%$, oesophageal atresia, malrotation of the bowel $13 \%$, jejunal atresia and anal hypoplasia. Respiratory disorders can include tracheoesphageal fistula and absence of one lung. Neurologic disorders include myelomeningocoele and en-

Table: Summary of echocardiographic/ chest X-ray/abdominal situs and electrocardiogram findings

\begin{tabular}{|c|c|c|c|c|c|}
\hline Case & Age (years) & Gender & $\begin{array}{l}\text { Echocardiographic Findings } \\
\text { Electrocardiogram }\end{array}$ & Chest X-ray & Abdominal situs \\
\hline 1 & 32 & $\mathrm{~F}$ & $\begin{array}{l}\text { Anomalous systemic venous drainage } \\
\text { Anomalous pulmonary venous drainage } \\
\text { Complete AVSD. with common atria } \\
\text { Two atrioventricular valves } \\
\text { Multiple muscular "Swiss cheese" VSD } \\
\text { Pulmonary valve stenosis }\end{array}$ & $\begin{array}{l}\text { Dextrocardia } \\
\text { Hyparterial } \\
\text { bronchi } \\
\text { Cardiomegaly }\end{array}$ & $\begin{array}{l}\text { Gastric bubble opposite to cardiac apex } \\
\text { Situs inversus of liver and spleen }\end{array}$ \\
\hline 2 & 29 & M & $\begin{array}{l}\text { Patent ductus arteriosus } \\
\text { Pulmonary hypertension }\end{array}$ & $\begin{array}{l}\text { Levocardia } \\
\text { Hyparterial } \\
\text { bronchi Cardiomegaly }\end{array}$ & Normal \\
\hline 3 & 17 & $\mathrm{~F}$ & Secundum ASD & $\begin{array}{l}\text { Levocardia } \\
\text { Hyparterial } \\
\text { bronchi }\end{array}$ & Large spleen \\
\hline 4 & 14 & $\mathrm{~F}$ & $\begin{array}{l}\text { Anomalous systemic venous drainage } \\
\text { Anomalous pulmonary venous drainage } \\
\text { Complete AVSD with common atria } \\
\text { Common atrioventricular valve (CAVV) } \\
\text { CAVV stenosis and regurgitation } \\
\text { Pulmonary valve stenosis }\end{array}$ & $\begin{array}{l}\text { Levocardia } \\
\text { Cardiomegaly }\end{array}$ & $\begin{array}{l}\text { Gastric bubble to right opposite to } \\
\text { cardiac apex Short P-R interval }\end{array}$ \\
\hline
\end{tabular}

AVSD: atrioventricular septal defect; ASD: atrial septal defect; RAD: right axis deviation; RVH: right ventricular hypertrophy; RAE: right atrial enlargement; BVH: biventricular hypertrophy; LAD: left atrial enlargement 
cephalocoele $4 \%$, microcephaly and hydrocephalus. Six per cent have genitourinary anomalies. Left atrial isomerism is associated with a number of syndromes including Klippel-Fiel and vertebral anomalies (2\%), hypothyroidism, Cornelia de Lange and epidermolysis bullosa $(3,4)$.

The aforementioned conditions highlight that LAI is usually associated with severe non-cardiac and complex cardiac lesions. Hence, presentation and survival is totally dependent on the co-morbid features and $61 \%$ usually die in infancy. Survival up to 30 years of age with intervention is about $63 \%$. Survival to adolescence and adulthood without non-cardiac lesions, as in the index cases, and without intervention is secondary to associated minor lesions or innate combination of cardiac lesions that protect the heart and lungs from congestive cardiac failure and rapid, severe development of pulmonary hypertension (1-4). Hence, the focus is on the echocardiographic findings only, which facilitated longevity, in the four index Afro-Caribbean cases, none of whom has had an intervention.

\section{CASE REPORTS}

\section{Case 1}

Index case number one is a 32-year old Afro-Caribbean female patient who was diagnosed in early childhood after an incidental cardiac murmur was noted. She has no history of palpitations, functions at New York Heart Association (NYHA) II, is on no medical therapy and has had no intervention previously. The index case is the only member of the family with LAI and she has no dysmorphic features. Electrocardiogram showed superior $\mathrm{P}$ axis with left axis deviation and biventricular hypertrophy and chest X-ray showed hyparterial bronchi, confirmed dextrocardia with abnormal abdominal situs with gastric bubble to the left (opposite to the cardiac apex), liver to the left and spleen to the right (Fig. 1). There was mild scoliosis. Transthoracic echocardiogram confirmed LAI with aorta anterior to the hemiazygous vein on the same left-hand side of the spine in the subcostal cross-sectional view and confirmed clinical and radiological sign of dextrocardia, in conjunction with complete atrioventricular septal defect and common atria. She had anomalous systemic and pulmonary venous drainage with left superior venae cava to left-sided atria and pulmonary veins to both right and left-sided atria. She also had four small muscular "Swiss cheese" ventricular septal defects, all with left to right restrictive shunts. Aorta was posterior and to the left with left aortic arch. Mild pulmonary stenosis of $1.3 \mathrm{~m} / \mathrm{s}$ was noted as well as normal right ventricular, pulmonary pressures and normal ventricular function.

\section{Case 2}

Index case number two is a 29-year old Afro-Caribbean male with no dysmorphic features or palpitations and functioning at NYHA II. His ECG showed right atrial enlargement, QRS right axis deviation and biventricular hypertrophy using the Katz-Wachtel criteria. He had normal cardiac and abdominal situs on chest X-ray. There were hyparterial bronchi, an in-

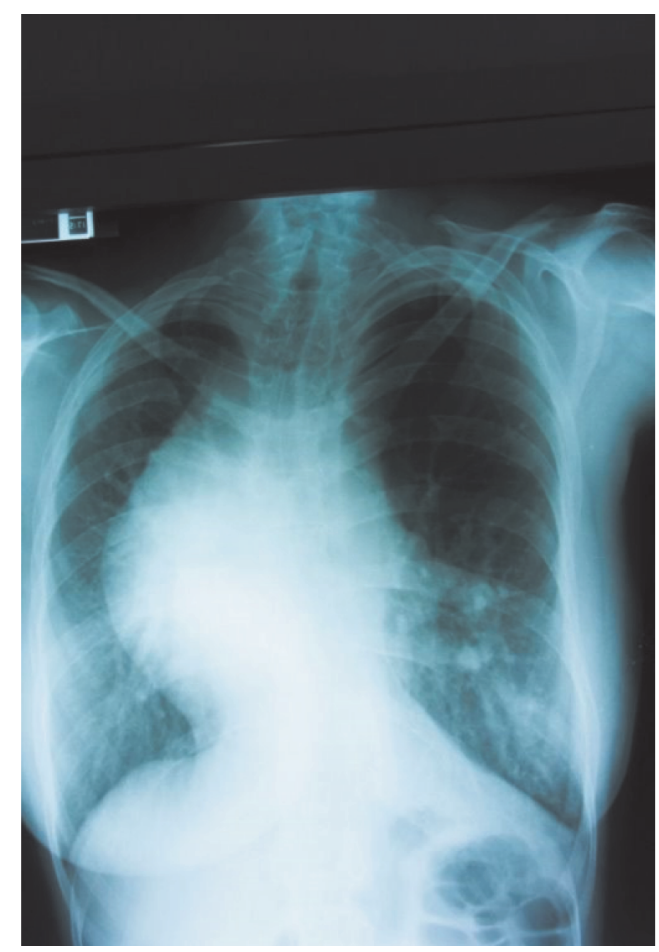

Fig. 1: Dextrocardia with gastric bubble opposite to the cardiac apex, hyparterial bronchi, left-sided liver and right-sided spleen.

creased cardio-thoracic ratio (CTR 14.5:26.2), prominent pulmonary artery and vasculature with no peripheral pruning, rounded apex and mild scoliosis (Fig. 2). Transthoracic crosssectional view of the aorta and inferior vena cava was normal with aorta to the left of the spine and connection of the inferior vena cava (IVC) to the right atrium. Ductus arteriosus (PDA) was the main cardiac anomaly with right to left shunt with pul-

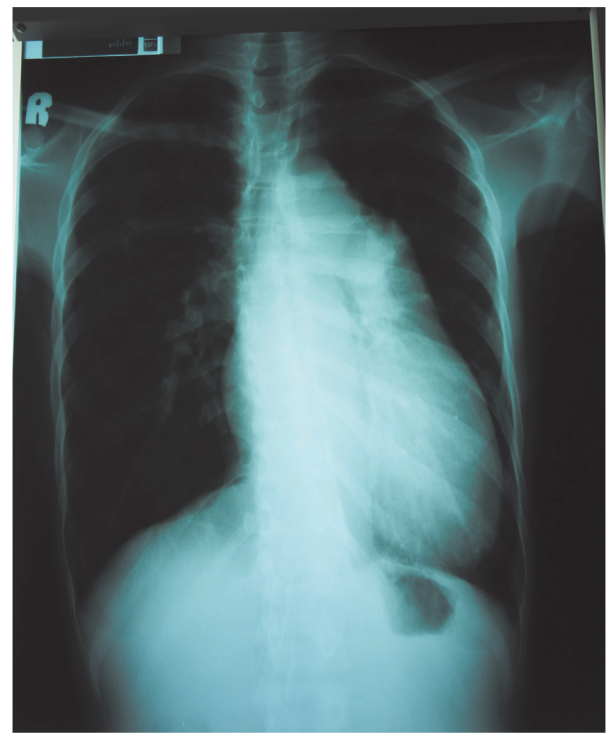

Fig. 2: Normal cardiac and abdominal situs, hyparterial bronchi, cardiomegaly and prominent pulmonary trunk and arteries. 
monary hypertension syndrome with high right ventricular and pulmonary artery pressures. He had normal ventricular function. Cardiac catheterization confirmed hemiazygous continuation to superior vena cava and descending aortic desaturation from right to left shunt across the PDA. There was interruption of IVC to right atrium as the catheter was unable to have direct access to the upper IVC, noted to be on transverse subcostal view connected to same.

\section{Case 3}

Index case number three is a 17-year old Afro-Caribbean female with moderate to severe developmental retardation who was noted to have an incidental cardiac murmur and no history of palpitations. The electrocardiogram was normal. Chest $\mathrm{X}$-ray showed hyparterial bronchi, normal cardiac situs and CTR ratio and mild scoliosis. There was normal position of liver, gastric bubble and a large spleen (Fig. 3). She functioned at NYHA I level. Transthoracic echocardiogram showed LAI with aorta anterior to the hemiazygous vein on the same lefthand side of the spine in the subcostal cross-sectional view. The only other intra-cardiac defect noted was a secundum atrial septal defect, $1.08 \mathrm{~cm}$, with a left to right shunt; there was normal right ventricular and pulmonary artery pressures with normal ventricular function.

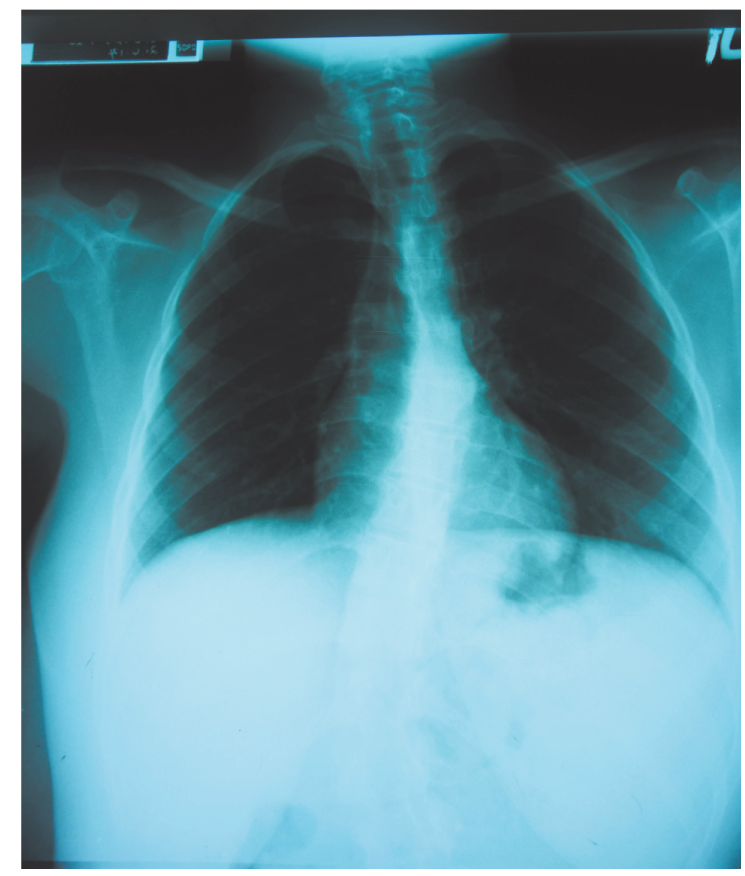

Fig. 3: Normal cardiac and abdominal situs, hyparterial bronchi and large spleen.

\section{Case 4}

Index case number four is a 14-year old Afro-Caribbean female diagnosed in early childhood with an incidental cardiac murmur. She has no dysmorphic features, no palpitations and functions at NYHA I and NYHA II on exertion. Electrocardiogram showed normal $P$ axis, left axis deviation of QRS axis with incomplete right bundle branch block and left ventricular hypertrophy. Chest X-ray showed normal cardiac situs with an increase in the cardiothoracic ratio (CTR 13:23), prominent pulmonary trunk and vasculature with no pruning. The abdominal situs showed gastric bubble to the right (opposite to the cardiac apex) and liver and spleen in normal positions (Fig. 4). Transthoracic echocardiogram showed LAI with aorta anterior to the hemiazygous vein on the same left-hand side of the spine in the subcostal cross-sectional view, as in index cases one and three. There were no inferior vena cavae with direct communication of hepatic vein to the right-sided left atrium. Chest X-ray had normal cardiac and abdominal situs, complete atrioventricular septal defect with a common atrioventricular valve (CAVV) with CAVV stenosis of $3.15 \mathrm{~m} / \mathrm{s}$, CAVV regurgitation of $5.16 \mathrm{~m} / \mathrm{s}$ and mild pulmonary valve stenosis of 1.78 $\mathrm{m} / \mathrm{s}$. She had anomalous pulmonary venous drainage with pulmonary veins draining into the left-sided atrium. There was anomalous systemic venous drainage with bilateral superior vena cava (SVC), with right SVC to right-sided atrium and left SVC to coronary sinus, with no bridging vein. There was trivial pulmonary regurgitation, bilateral ventricular hypertrophy with normal ventricular function.

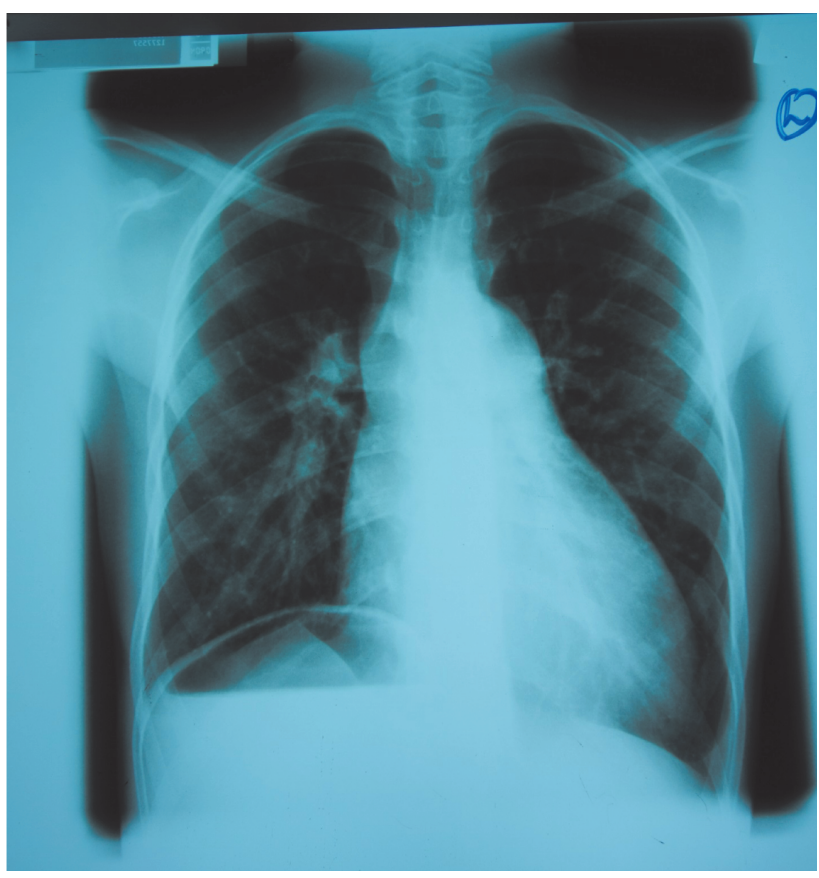

Fig. 4. Normal cardiac situs, cardiomegaly, prominent pulmonary trunk and arteries. Abdominal situs: normal position of liver and spleen with gastric bubble to the right (opposite to the cardiac apex).

\section{DISCUSSION}

The four index cases echocardiographically show a mixture of complex cardiac and isolated cardiac defects, summarized in the Table. It is the first time that isolated PDA as the only cardiac lesion has been associated with LAI. Deanfield et al, at Great Ormond Street and using over penetrated chest X-rays, noted a $10 \%$ incidence of isomerism. Caruso and Becker had a number of cases of LAI, with no bronchial symmetry and 
hence confirmed that LAI may not be able to be diagnosed on chest X-rays only. Abnormal abdominal situs and transverse subcostal view with aorta anterior to the hemiazygous vein were diagnostic in three of four index cases $(1,2)$. Diagnostic clues to LAI in Figs. 1-4 demonstrate the corresponding varied findings on chest X-ray of the index cases including hyparterial bronchi in cases 1,2 and 4, abnormal cardiac situs in index case 1 with gastric bubble opposite to the cardiac apex and abnormal right-sided position of gastric bubble in case 4 . Gilljam et al noted a $0.4 \%$ incidence and $41 \%$ termination after fetal diagnosis with $20 \%$ dying in the postnatal period, indicating higher incidence in fetal life. There has been diagnosis of LAI in twins (4). Eronen et al interestingly noted that $6 \%$ of mothers of patients with LAI have diabetes and there is a female preponderance, noted by both Eronen et al and Gilljam et al $(3,4)$. Of patients who had no intervention, $49 \%$ died within the first year of life (1-6). Many LAI cases, with minor cardiac or non-cardiac anomalies, are usually diagnosed in adulthood and there is $75 \%$ mortality up to age 15 years in this group (4). Left atrial isomerism has not been a focussed feature of assessment in the Caribbean, hence the true incidence and prevalence is not known and may be much higher than seen currently. These four Afro-Caribbean index cases with LAI have a rare congenital anomaly, usually associated with major or minor congenital cardiac lesions, and $61 \%$ usually die in infancy and childhood secondary to complications of the associated major congenital cardiac, dysrhythmia and non-cardiac lesions. The four index cases highlight the myriad of innate combination of cardiac lesions that prevents early development of pulmonary hypertension and congestive cardiac failure, and non-development of dysrhythmias that facilitate survival into adulthood of this rare cardiac condition. Included is the only documented case of isolated PDA with LAI without intervention. Fascinating diagnostic chest X-ray findings of the LAI index cases are presented as teaching tools. They are the first cases of LAI documented in AfroCaribbeans.

\section{REFERENCES}

1. Anderson RH, Macartney FJ, Shineboume EA, Tynan M. Atrial isomerism. In: Paediatric Cardiology: Vol 1. London: Churchill Livingstone; 1987: 473-524.

2. Kirklin JW, Barratt-Boyes BG. Cor triatriatum. In: Cardiac Surgery: Vol 1. New York: Churchill Livingstone; 1993: 1585-96.

3. Eronen MP, Aittomaki KA, Kajantie EO, Sairanen HI. Outcome of left atrial isomerism at a single institution. Pediatr Cardiol 2013; 34: 302-7.

4. Gilljam T, McCrindle BW, Smallhorn JF, Williams WG, Freedom RM. Outcomes of left atrial isomerism over a 28 -year period at a single institution. J Am Coll Cardiol 2000; 36: 908-16.

5. Hirooka K, Yagihara T, Kishimoto H, Isobe F, Yamamoto F, Nishigaki K et al. Biventricular repair in cardiac isomerism. J Thorac Cardiovasc Surg 1995; 109: 530-5.

6. Uemura H, Ho SY, Anderson RH, Devine WA, Smith A, Shinohara T et al. The surgical anatomy of coronary venous return in hearts with isomeric atrial appendages. J Thorac Cardiovasc Surg 1995; 110: 436-44. 